\title{
Short Report: \\ Trends and applicant characteristics in New Zealand: Radiation oncology versus radiology
}

\author{
Y. Alamri ${ }^{1,2}$, K. Alsabli \& D. Ravindran ${ }^{4}$
}

\begin{abstract}
Introduction: Previous research has projected future shortages in radiation oncologists in Australia. Anecdotal evidence also suggests a similar pattern in New Zealand, however shortages in the radiology workforce have not been forecast to date. The present study aimed to examine the trends in applications for radiation oncology and radiology positions in New Zealand.
\end{abstract}

Methods: Data were collected on vocational training applicants and senior medical officer (SMO, consultant) positions from 2009 to 2016. Data were obtained from publicly-available data on the New Zealand Ministry of Health and Royal Australian and New Zealand College of Radiologists (RANZCR) websites.

Results: Compared with radiation oncology, applications to radiology significantly outnumbered the available positions - a trend that escalated between 2009 and 2016. In addition, the radiation oncology SMO workforce in New Zealand attracted progressively fewer local graduates (i.e., more international medical graduates) compared with radiology over the period studied.

Conclusions: This is the first study to shed light on trends in applications to the two specialties overseen by RANZCR in New Zealand. Future efforts should focus on attracting more trainees to radiation oncology and addressing factors underlying the apparent discrepancies between the two specialties, as well as the mental health and wellbeing of trainees.

\footnotetext{
New Zealand Brain Research Institute, Christchurch, New Zealand

Canterbury District Health Board, Christchurch, New Zealand

The Prince of Wales Clinical School, University of New South Wales, NSW, Australia

Department of Radiology, The Royal Prince Alfred Hospital, Sydney, NSW, Australia
}

\section{Correspondence}

Yassar Alamri, MBChB, PhD

Medical Registrar, Canterbury District Health Board

Honorary Clinical Lecturer, Department of Medicine, University of Otago

Christchurch Public Hospital

2 Riccarton Ave

Riccarton

Christchurch 8011

New Zealand

Tel: +6421750015

Fax: +6433786080

Email: yassar.alamri@nzbri.org 
Keywords: radiology; radiation oncology; junior doctor; New Zealand; career choice

\section{Introduction}

The Royal Australian and New Zealand College of Radiologists (RANZCR) oversees the training of both radiation oncology and radiology across Australia and New Zealand; training in these specialties is also available in Singapore. Both radiology and radiation oncology remain among the five most competitive specialties in the US residency match (National Resident Matching Program ${ }^{\bullet}$ 2017). In Canada, training posts are consistently filled for these specialties, even though the number of available training positions differs in accordance with the predicted workforce need (Lalani et al., 2017). In Australasia, final-year medical students were found to have significant deficits in their awareness of radiation oncology and had rated oncology among the worst taught subjects within the medical course (Bravery et al., 2019). Interest in either specialty as a career choice in Australia or New Zealand has not been formally assessed to date.

There appears to be a discrepancy in the rates of successful recruitment to radiology and radiation oncology in Australasia. Previous research has projected future shortages in radiation oncologists in Australia, partly due to under-recruitment of new trainees (Schofield et al., 2012). Anecdotal evidence also suggests a similar pattern in New Zealand (Karen Schaab, personal communication, May 22, 2018). Shortages in the radiology workforce, on the other hand, have not been forecast to date. With the increasing demand for qualified practitioners in both specialties (e.g., greater scope for newer radiation treatment modalities for various cancers and an increase in interventional radiological procedures), future workforce shortages would be inevitable if recruitment of young doctors into these specialties is not enhanced.

The present study aimed to examine the trends in applications to radiation oncology and radiology positions in New Zealand. Our a priori hypothesis was that successful application to radiology has been getting significantly harder compared with radiation oncology due to a burgeoning interest in radiology but a stagnant interest in radiation oncology. We present the results in the context of the available literature in order to inform educators and interested policymakers.

\section{Methods}

\section{Data sources}

Data were collected on the total number as well as the number of successful vocational training applicants to radiology and radiation oncology. Data on senior medical officer (SMO, consultant or attending) positions and place of training were also collected. Freely-available data were obtained from the New Zealand Ministry of Health (2017) and RANZCR (2017) websites. Only data pertaining to New Zealand training applicants and SMOs between 2009 and 2016 were included. 
RADIATION ONCOLOGY VERSUS RADIOLOGY

\section{Statistical analysis}

Descriptive statistics and linear regression analysis were used to analyse the data. Statistical significance was determined if type I error rate was $<5 \%(p<0.05)$. All analyses were performed using SPSS Statistics ${ }^{\circledR}$ software package (version 22.0.0.0).

\section{Results}

\section{Radiation oncology}

Between 2009 and 2016, the mean number of applicants to radiation oncology training was $5( \pm 3.1)$ applicants/year. The mean number of available training positions was 4.3 $( \pm 2.4)$ positions/year.

Between 2009 and 2015, there had been a mean of 3 ( \pm 1.6) SMO positions/year. As of 2016, the number of radiation oncology SMOs in New Zealand was 66. In 2013, the percentage of female radiation oncologists was $29 \%$.

\section{Diagnostic and interventional radiology}

Between 2009 and 2016, the mean number of applicants to radiology training was 40.6 $( \pm 7.5)$ applicants/year. The mean number of available training positions was $17.8( \pm$ 2.1) positions/year.

Between 2009 and 2016, there had been a mean of $18.3( \pm 9.5)$ SMO positions/year. As of 2016, the number of radiology SMOs in New Zealand was 468. In 2012, the percentage of female radiologists was $31.3 \%$.

\section{Comparative analysis}

The competitiveness (as measured by the ratio of applicant numbers to positions offered) was significantly higher for radiology $(2.3 \pm 0.5$ applicants per position) than radiation oncology $(1.1 \pm 0.3$ applicants per position) training $(p<0.0001)$. In addition, through the years, competitiveness significantly increased for radiology $(p=0.02)$ but not radiation oncology applications $(p=0.2)$. See Figure 1 .

The mean age of SMOs was not significantly different between the two specialties (49 years for both). International medical graduates held a significantly higher percentage of the radiation oncology SMO workforce (54\%) than radiology $(41 \%, p=0.04)$.

\section{Discussion}

This is the first study to shed light on application trends of the two specialties overseen by the RANZCR in New Zealand. Compared with radiation oncology, applications to radiology significantly outnumbered the available positions-a trend that escalated between 2009 and 2016. In addition, the radiation oncology SMO workforce in New Zealand attracted progressively fewer local graduates (i.e., more international medical graduates) compared with radiology over the period studied. 
RADIATION ONCOLOGY VERSUS RADIOLOGY

\section{Figure 1}

Regression Analysis Demonstrating Significantly Increasing Demand for Radiology but Not Radiation Oncology Training Positions in New Zealand Between 2009 and 2016

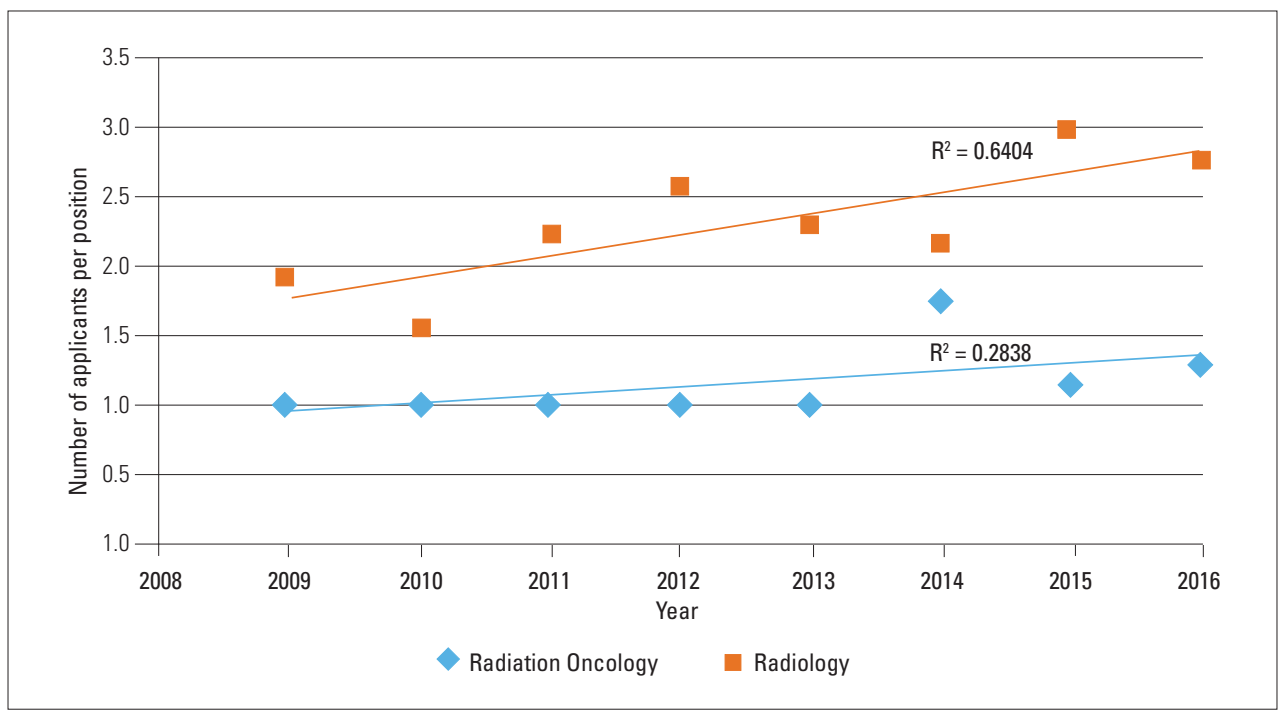

Our findings support anecdotal evidence of difficulties recruiting New Zealand medical graduates to the field of radiation oncology. Whilst the exact cause/s for the observed trends are not known, several speculations can be made from reviewing the literature.

Several studies have attempted to ascertain specific factors associated with medical students' choice of specialty. It is unlikely that a single factor solely affects that decision; rather, a constellation of intrinsic (e.g., personal interest) and extrinsic (e.g., perceived prestige or potential income) factors are at play (Jeffe et al., 2014). A survey of all medical students attending the Christchurch campus of the University of Otago $(\mathrm{n}=204)$ in 2000 revealed that $18 \%$ ranked radiology as one of their top three career choices (Gill et al., 2001). No reference to radiation oncology was made. The level of exposure to radiation oncology for medical students in Australia and New Zealand (Nicholls et al., 2018) might be a contributing factor to the trend observed in our study. Other factors are also likely to play a role in future specialty choice by medical students, including the availability of mentors and role models, as well as specialty-specific interest groups (Kost et al., 2019).

With improved work-life balance being increasingly advocated, it could be speculated that lifestyle factors, such as work hours, perceived stress and on-call duties play a role in career decisions (Ip et al., 2010). Ip et al. (2010) reported high job satisfaction among radiology trainees in Queensland, Australia. Australian and New Zealand trainees in radiation oncology, on the other hand, reported high levels of burnout and stress (Leung \& Rioseco, 2017). However, we acknowledge that the interaction between job satisfaction and burnout/stress is likely to be situational, complex and non-linear. 
Other factors may also contribute to the differences observed, although the literature is less robust. The length of training is 5 years for both programs (Ministry of Health, 2017) and is, therefore, unlikely to account for our findings. Similarly, New Zealand trainees are limited by contract provisions, and therefore, additional income from extra work is likely to be similar between trainees of both specialties. Future earning potential, on the other hand, might be a contributing factor, although no official data are available to enable meaningful comparisons.

Several limitations to our study should to be mentioned. The findings only reflect the status of both RANZCR's training programs in New Zealand between 2009 and 2016. A more complete picture should be obtained in future studies by the inclusion of a longer time period as well as data from Australia and Singapore.

Currently, the New Zealand Radiology Education Trust provides scholarships and awards to young medical graduates, in the hopes of sparking interest in RANZCR specialties - especially in radiation oncology (RANZCR, 2017). Future efforts should focus on addressing mental health and wellbeing in trainees whilst also addressing workplace, training and other structural and systemic factors. If successful, this should enhance recruitment of junior doctors into these specialties and combat any future calamities brought about by the anticipated shortage in the radiation oncology (and, to a lesser extent, radiology) workforce. Future surveys targeting medical students and junior medical staff's attitudes towards radiation oncology are expected to identify perceived barriers and help ascertain whether our assertions are true.

\section{Funding and conflicts of interest statement}

No conflicts of interest or funding to declare.

\section{References}

Bravery, B. D., Shi, K., Nicholls, L., Chelvarajah, R., Tieu, M. T., Turner, S., \& Windsor, A. (2019). Oncology and radiation oncology awareness in final year medical students in Australia and New Zealand. Journal of Cancer Education, Advance online publication. https://doi.org/10.1007/s13187-019-01586-3

Gill, D., Palmer, C., Mulder, R., \& Wilkinson, T. (2001). Medical student career intentions at the Christchurch School of Medicine: The New Zealand wellbeing, intentions, debt and experiences (WIDE) survey of medical students pilot study. Results part II. New Zealand Medical Journal, 114(1142), 465-467.

Ip, S. W., Ko, H. S., \& Applegate, K. E. (2010). Factors influencing career choices in radiology trainees in Queensland, Australia. Journal of Medical Imaging and Radiation Oncology, 54(2), 93-99. https://doi.org/10.1111/j.17549485.2010.02145.x

Jeffe, D. B., Andriole, D. A., Wathington, H. D., \& Tai, R. H. (2014). Educational outcomes for students enrolled in $\mathrm{MD}-\mathrm{PhD}$ programs at medical school matriculation, 1995-2000: A national cohort study. Academic Medicine, 89(1), 84-93. http://www.ncbi.nlm.nih.gov/pmc/articles/PMC3874256/pdf/ nihms480783.pdf 
Kost, A., Bentley, A., Phillips, J., Kelly, C., Prunuske, J., \& Morley, C. P. (2019). Graduating medical student perspectives on factors influencing specialty choice: An AAFP national survey. Family Medicine, 51(2), 129-136. https://doi. org/10.22454/FamMed.2019.136973

Lalani, N., Cummings, B., Halperin, R., Rakovitch, E., Brundage, M., Vigneault, E., \& Milosevic, M. (2017). The practice of radiation oncology in Canada. International. Journal of Radiation Oncolology, Biology, Physics, 97(5), 876-880. https://doi.org/10.1016/j.ijrobp.2016.11.055

Leung, J., \& Rioseco, P. (2017). Burnout, stress and satisfaction among Australian and New Zealand radiation oncology trainees. Journal of Medical Imaging and Radiation Oncology, 61(1), 146-155. https://doi.org/10.1111/1754-9485.12541

Ministry of Health. (2017). Health workforce. Retrieved July 23, 2017, from http:// www.health.govt.nz/our-work/health-workforce

National Resident Matching Program . (2017). Results and data: 2017 main residency match ${ }^{\circledR}$. http://www.nrmp.org/wp-content/uploads/2017/06/Main-Match-Resultsand-Data-2017.pdf

Nicholls, L., Bravery, B., Chelvarajah, R., Shi, K., Tieu, M. T., Turner, S., \& Windsor, A. (2018). The status of radiation oncology teaching in Australian and New Zealand medical schools. Journal of Medical Imaging and Radiation Oncology, 62(6), 828-834. https://doi.org/10.1111/1754-9485.12788

Schofield, D., Callander, E., Kimman, M., Scuteri, J., \& Fodero, L. (2012). Projecting the radiation oncology workforce in Australia. Asian Pacific Journal of Cancer Prevention, 13(4), 1159-1166.

The Royal Australian and New Zealand College of Radiologists (RANZCR). (2017). Trainees' section. Retrieved July 23, 2017, from https://www.ranzcr.com/trainees 